\title{
A EDUCAÇÃO INFANTIL E O PLANO NACIONAL DE EDUCAÇÃO: AS PROPOSTAS DA CONAE 2010
}

\author{
Lívia Maria Fraga Vieira*
}

\begin{abstract}
RESUMO: Nosso objetivo é destacar alguns aspectos da oferta de educação infantil no país nos últimos 10 anos, tendo em vista as metas do Plano Nacional de Educação (PNE) de 2001. Transcorrido esse período, que se caracterizou pela implementação de políticas que objetivaram integrar creches e pré-escolas nos sistemas de ensino, em consonância com o marco legal pós-Lei de Diretrizes e Bases da Educação Nacional (LDBEN, 1996), nós percebemos permanências, redefinições e tensōes. Os subsídios para a elaboração do novo PNE, deliberados na Conferência Nacional de Educação (CONAE) no último abril, redimensionam metas para esta etapa da educação básica, no propósito mais geral de estabelecer as bases de um novo pacto federativo, visando à construção de um Sistema Nacional de Educação. Questionamos se as metas sugeridas pela CONAE para a educação da criança pequena consideram as tendências de cobertura de acesso observadas nos últimos 10 anos e se promovem investimento na perspectiva do marco legal que vem sendo construído nas duas últimas décadas.
\end{abstract}

Palavras-chave: Educação infantil. Creches. Plano Nacional de Educação. CONAE.

\section{Pre-sChOOL EDUCATION AND THE NATIONAL PLAN FOR EDUCATION: THE 2010 CONAE'S PROPOSALS}

ABSTRACT: This paper highlights some aspects regarding the supply of pre-school education in Brazil, these last 10 years, bearing in mind the goals of the 2001 National Plan for Education (PNE).

Doutora em Sociologia da Educação e professora do Programa de Pós-Graduação em Educação e do Departamento de Administração Escolar da Faculdade de Educação, Universidade Federal de Minas Gerais (UfMG). E-mail: liviafraga@globo.com 
After the period characterized by the implementation of policies aimed at integrating creches (daycare center) and pre-schools into the teaching systems, in line with the legal goals proposed after the National Education Law of Guidelines and Basis (LDBEN, 1996), we have perceived permanencies, redefinitions and tensions. The elements to draw up the new PNE, deliberated within the Conference on National Education (CONAE), last April, resize the goals for this stage of basic education, with a more general purpose of establishing bases for a new federative pact aimed at the development of a National System of Education. We wonder if the goals suggested by the CONAE for the education of little children consider the tendencies of access coverage observed these last 10 years and if they promote investments in the perspective of the legal goals that have been developed these last two decades.

Key words: Pre-school education. Creches. National Plan for Education. CONAE.

anham proeminência e visibilidade nos atuais planos do governo federal as ações e metas que se referem à educação infantil. Temos metas vinculadas ao Plano de Aceleração do Crescimento Programa 2, programa do governo federal que abrange diferentes setores econômicos e sociais. A elas estão articuladas as metas do Plano de Desenvolvimento da Educação (PDE), programa ministerial lançado em 2007. Está em elaboração o novo Plano Nacional de Educação (PNE) para a década 2011-2020, segundo propostas referendadas na Conferência Nacional de Educação (CONAE), em abril último. O Documento Final concernente, no propósito da construção de um Sistema Nacional de Educação, repõe a definição de um regime de colaboração entre os entes federados no enfrentamento das desigualdades sociais e educacionais, conforme Emenda Constitucional n. 59/2009, e adota uma referência para a garantia de padrôes mínimos de qualidade na educação - o custo aluno-qualidade (CAQ).

Nosso intuito, neste artigo, foi destacar alguns aspectos da oferta de educação infantil no país, nos últimos 10 anos, nos referenciando nas metas do PNE sancionado em 2001, a fim de discutir as novas proposições constantes do Documento Final da CONAE para a próxima década da educação. Discutimos, especialmente, aspectos relacionados à 
cobertura do atendimento em creches e pré-escolas, à formação dos professores e às proposiçôes para a política de convênios na área.

A análise das metas debatidas e deliberadas na CONAE deve levar em conta que a educação infantil está na pauta das políticas federais de desenvolvimento, e de educação, em particular, podendo ser isso um aspecto promissor para que se alcance a implementação de políticas que reconheçam a necessidade de amenizar desigualdades sociais diversas. Assim, as metas de investimentos na construção de creches e pré-escolas, constantes no PAC 2, merecem ser resgatadas:

Duas ações em educação farão parte do segundo Programa de Aceleração do Crescimento, o PAC 2, lançado nesta segunda-feira, 29 [de março de 2010]. Uma delas é a construção e reestruturação de escolas de educação infantil, por meio do programa Proinfância. (...) As ações em educação fazem parte de um dos subgrupos do PAC, chamado Comunidade Cidadã (...). Com o Proinfância, programa do MEC que existe desde 2007, a intenção é ampliar a oferta de educação pública para crianças de zero a cinco anos, por meio de construção de creches e pré-escolas e aquisição de equipamentos e mobiliário. Até 2009, foram conveniadas 1.722 unidades. Em 2010, a previsão é de 800 unidades. Incluído no PAC 2, o programa permitirá a construção de mais 1,5 mil escolas de educação infantil por ano, até 2014 , totalizando 6 mil. Cada unidade custará entre $\mathrm{R}$ \$ 620 mil e $\mathrm{R}$ \$ 1,3 milhão. A previsão de investimento total em quatro anos é de R \$ 7,6 bilhões. O deputado federal Angelo Vanhoni, presidente da Comissão de Educação e Cultura, enfatiza que o PAC 2 será essencial para concretizar as metas definidas pelo Plano Nacional da Educação debatido durante a Conferência Nacional da Educação. (Agência Bom Dia, 2010) ressaltaram a

$\mathrm{Na}$ CONAE, as metas quantitativas em relação à educação infantil

(...) garantia de aporte financeiro do governo federal para a construção, reforma, ampliação de escolas e custeio com pessoal, para aumento da oferta de vagas em $50 \%$, até 2012 , e a universalização do atendimento à demanda manifesta, até 2016, especificamente às crianças da faixa etária de 0 a 3 anos de idade, em período integral, a critério das famílias, assegurando progressivamente seu atendimento por profissionais com nível superior e garantia de formação continuada. (Brasil/MEC, 2010, p. 68)

Relevamos o fato positivo de a educação infantil receber tratamento integrado às metas para a educação básica e para o ensino superior, 
estas últimas referentes à formação de professores, sendo inferida nos seis eixos que compóem o Documento Final e que orientaram as discussôes nas conferências preparatórias da CONAE:

Eixo I - Papel do Estado na Garantia do Direito à Educação de Qualidade: Organização e Regulação da Educação Nacional.

Eixo II - Qualidade da Educação, Gestão Democrática e Avaliação.

Eixo III - Democratização do Acesso, Permanência e Sucesso Escolar.

Eixo IV - Formação e Valorização dos/das Profissionais da Educação.

Eixo V - Financiamento da Educação e Controle Social.

Eixo VI - Justiça Social, Educação e Trabalho: Inclusão, Diversidade e Igualdade.

Em relação à Garantia do Direito à Educação de Qualidade, Eixo I, concebe-se que o Sistema Nacional de Educação deve prover elementos primordiais para o atendimento educacional, elencados em 26 itens. Excetuando os que se referem à avaliação de desempenho dos alunos, os demais se aplicam a todas as etapas e níveis do ensino brasileiro. Vemos que a educação infantil recebe enfoque abrangente em relação ao provimento de padrões mínimos de qualidade, sendo pautada pelos requisitos de uma gestão democrática dos serviços, adequados aos usuários e ao corpo dos profissionais da educação.

Em relação à democratização do acesso, da permanência e do sucesso escolar, em todos os níveis e modalidades de educação, a educação infantil é foco de atenção específica no Eixo III, com ênfase nos seguintes aspectos, além das já referidas metas de cobertura para os próximos anos:

- "consolidação de políticas, diretrizes e ações destinadas à ampliação do acesso à educação infantil, visando à garantia do direito à educação de qualidade às crianças de 0 a 5 anos de idade" (Brasil/MEC, 2001, p. 68). O documento ressalta que o Brasil não pode correr o risco de deixar de priorizar o aumento de matrículas na etapa da creche em favor da expansão das matrículas na pré-escola, tendo em vista a extensão da obrigatoriedade escolar para crianças a partir de 4 anos de idade. "A educação infantil não pode ser cindida"; 
- "implementação de uma coordenação efetiva e atuante dos órgãos da União, estados, Distrito Federal e municípios, com a ampliação, apoio e otimização dos processos de organização, gestão e universalização gradativa dessa etapa da educação básica";

- "realização do censo da educação infantil, garantindo que todas as instituições de educação infantil, públicas e privadas sejam incluídas no Censo Escolar e em outros levantamentos de informações educacionais";

- "garantia de que o atendimento das crianças seja feito exclusivamente por profissionais devidamente habilitados/as, conforme a legislação vigente";

- "o debate, o repensar, a revisão e a modificação, de modo integrado, de todo o currículo das primeiras etapas da educação básica, em decorrência do ingresso aos seis anos no ensino fundamental, tornado obrigatório";

- "a discussão e proposição de diretrizes para as políticas de convênios com entidades privadas, de tal forma que o MEC assuma a coordenação dessa discussão";

- "a ampliação da oferta de educação infantil pelo poder público, extinguindo progressivamente o atendimento por meio de instituições conveniadas" (idem, ibid.).

A educação infantil também está referida no enunciado sobre a universalização e a ampliação do ensino fundamental (EF) para nove anos. Defende-se estabelecer, por meio de lei específica, "que o ingresso no EF só ocorra aos seis anos completos ou a completar até o início do ano letivo (no máximo até março do ano de ingresso), admitindose a possibilidade de a criança nesta faixa etária manter-se na rede física da educação infantil com o mesmo currículo e o profissional que já a atendia; (...)" (Brasil/MEC, 2010, p. 69). Essas questões exigiriam melhor tratamento, que fogem ao escopo deste artigo. De qualquer forma, a necessidade de afirmar o corte de idade do ingresso no EF parece ser decorrência dos variados entendimentos sobre o assunto observados nos sistemas de ensino, entendimentos que têm promovido antecipação de escolaridade e a inserção de crianças menores sem a presença de 
condições físicas e pedagógicas que as acolham com qualidade. As imprecisões do texto constitucional trazidas pela Emenda Constitucional n. 53/2006, que redefine a faixa de idade da educação infantil para crianças de 0 até 5 anos, justificam a pertinência dessa afirmação. Recentemente, ocorreu intensa mobilização da área educacional para que não se aprovasse, na Câmara dos Deputados, Projeto de Lei que havia sido aprovado no Senado, que antecipava para a partir de cinco anos de idade a matrícula dos menores no ensino fundamental. As repercussões observadas na mídia impressa em relação ao Parecer CNE/CEB n. 12/ 2010, ainda não homologado, sobre matrícula no ensino fundamental e na educação infantil, nos dão outra medida das tensões presentes, envolvendo também as famílias, quando se busca redimir as ambiguidades em relação à idade de ingresso no ensino fundamental, constantes do texto constitucional.

No Eixo V, financiamento da educação e controle social, afirmase que

(...) a política de financiamento da educação básica, nos termos de um sistema nacional de educação, deve, obrigatoriamente, amparar-se na definição de um custo aluno-qualidade ( $\mathrm{CAQ})$, construído com a participação da sociedade civil, capaz de mensurar todos os insumos necessários à educação de qualidade, superando as desigualdades regionais, com ênfase no investimento à valorização de todos/as os/as profissionais da educação básica. (Brasil/MEC, 2010, p. 109)

A implementação dessas definições é consensual na área educacional, tendo sido objeto do Parecer CNE/CEB n. 8/2010, aprovado em maio último, ainda não homologado. $\mathrm{O}$ aumento dos recursos para serem investidos em educação ganha respaldo na proposição

(...) de ampliar o investimento em educação pública em relação ao PIB, na proporção de, no mínimo, $1 \%$ ao ano, de forma a atingir, no mínimo, 7\% do PIB até 2011 e, no mínimo, 10\% do PIB até 2014, respeitando a vinculação de receitas à educação definidas e incluindo, de forma adequada, todos os tributos (impostos, taxas e contribuiçôes). (Brasil/MEC, 2010, p. 110)

O Documento Final da CONAE ressalta, entre as duas inovações trazidas pelo FUNDEB, a incorporação da creche conveniada nos recursos financeiros a serem repartidos no Fundo: "a atual taxa de atendimento 
da educação infantil, em especial na creche, dadas as metas expressas no PNE, justifica, nesse caso, a parceria do poder público com o segmento conveniado" (Brasil/MEC, 2010, p. 112).

Lembrando que as crianças de 4 e 5 anos atendidas pelas instituições conveniadas só serão cobertas com recursos do FUNDEB pelo prazo de 4 anos, a contar do início de sua implementação, o que implica absorção dessas matrículas pelo setor público, o documento acrescenta:

(...) em respeito ao princípio do recurso público para a escola pública, o número de matrículas em creches conveniadas deve ser congelado em 2014, e essa modalidade de parceria deve ser extinta até 2018, tendo que ser obrigatoriamente assegurado o atendimento da demanda diretamente na rede pública. Vale dizer que, no caso da educação infantil, a extensão da obrigatoriedade do ensino não pode significar prejuízo de investimentos na ampliação de matrículas nas creches - primeira etapa da educação básica e aquela que está mais distante de atingir as metas de atendimento estabelecidas pelo PNE. Nessa ótica, é fundamental a garantia de aporte financeiro do governo federal para construção, reforma, ampliação e custeio com pessoal para o aumento significativo da oferta de vagas. O objetivo é matricular $50 \%$ das crianças de 0 a 3 anos, até 2012 , e universalizar o atendimento da demanda manifesta, até 2016. (Brasil/ MEC, 2010, p. 112-113)

É, certamente, uma meta ambiciosa e que precisa ser analisada em relação às tendências de cobertura de atendimento apresentada pelas pré-escolas e, em especial, pelas creches, nos últimos 10 anos. A sua discussão requer considerar as metas que foram estabelecidas no atual PNE para o decênio 2001-2010.

\section{A educação infantil no PNE (2001)}

No PNE (2001), a educação infantil foi contemplada em 25 metas específicas. As de cobertura de atendimento estão sintetizadas na Tabela 1.

A implantação de um Programa Nacional de Formação dos Profissionais de Educação Infantil, com a colaboração da União, estados e municípios, das universidades, institutos superiores de educação e organizações não governamentais, também foi estabelecida, com as seguintes metas para formação de professores: que todos os professores, 
em cinco anos, tivessem habilitação específica de nível médio e, em dez anos, $70 \%$ tivessem formação específica de nível superior.

\section{Tabela 1}

Educação infantil: metas de cobertura do PNE/2001

\begin{tabular}{|l|c|c|}
\hline \multicolumn{3}{|c|}{ Metas do PNE/2001 } \\
\hline Prazos & $0-3$ anos & $4-6$ anos \\
\hline Em 5 anos atender & $30 \%$ & $60 \%$ \\
\hline Em 10 anos atender & $50 \%$ & $80 \%$ \\
\hline
\end{tabular}

Fonte: Brasil/MEC, 2001.

Buscou-se assegurar, igualmente, a destinação de recursos financeiros para a oferta pública de educação infantil, quando estabelecia que, em todos os municípios, além de outros recursos municipais, os $10 \%$ dos recursos de manutenção e desenvolvimento do ensino não vinculados ao Fundo de Manutenção e Desenvolvimento do Ensino Fundamental (FUNDEF) fossem aplicados, prioritariamente, na educação infantil.

O breve balanço da implementação das metas do atual PNE, realizado pelo Conselho Nacional de Educação - "Indicações para subsidiar a construção do Plano Nacional de Educação 2011-2010" - e que se sustentou em algumas avaliações empreendidas pela Câmara dos Deputados - Comissão de Educação e Cultura -, pelo próprio Conselho, pela $S E B / M E C$ e pelo INEP, evidenciou problemas que foram classificados em duas dimensões: externa e interna ao PNE.

Entre as dimensóes que se relacionam com as políticas implementadas na vigência do referido PNE, ressaltamos os seguintes principais problemas: pouca utilização do Plano no primeiro triênio após sua aprovação; pouca consideração dada ao Plano quando do estabelecimento das políticas de governo, gerando algumas concepçôes, ações, programas e políticas diferentes das estabelecidas no PNE; desarticulação entre o PNE e os planos setoriais de governo; dissociação entre o PNE e os planos estaduais e municipais de Educação; articulação tardia do 
PDE e do PAR com os princípios e metas do PNE; minimização da universalização da educação básica como direito; ausência de mecanismos para o acompanhamento e avaliação sistemáticos do PNE.

Nas questões internas ao Plano, apontaram-se, entre outros constrangimentos: a ausência de indicadores relativos às metas, para concretizar a possibilidade de acompanhamento e avaliação do desenvolvimento do PNE; a retirada dos mecanismos concretos de financiamento das metas, expressos no próprio Plano (vetos); a focalização no ensino fundamental; a pulverização de metas levando à fragmentação e dispersão das ações.

O documento destacou ainda que, apesar do PDE não ter sido articulado imediatamente ao PNE, algumas ações, programas e projetos concorreram para o alcance, total ou parcial, de muitas metas, especialmente as relativas à melhoria da qualidade do ensino, os quais abrangem direta ou indiretamente a educação infantil:

FUnDEB, Diretrizes para a Educação infantil; o Ensino Fundamental de nove anos; o Ensino Médio integrado à Educação Profissional; política nacional de Educação Especial; diversas políticas de inclusão e diversidade; expansão do Sistema Federal de Ensino, com os IFET e IFES; PNPG 2005-2010; Plano de Ações Articuladas - PAR; programas de alimentação, livro didático e de transporte escolar; Política e Plano Nacionais de Formação de Professores; a CAPES da Educação Básica; piso salarial nacional de professores; diretrizes de carreira, a instituição do Índice de Desenvolvimento da Educação básica - IDEB e diversos programas voltados para o desenvolvimento da gestão democrática. (Brasil/CNE, 2009, p. 6)

Comentamos brevemente, nos tópicos seguintes, os avanços e limites para o alcance das metas sobre acesso e formação de professores. Ressaltamos também as propostas para o novo PNE relativas aos convênios.

\section{Acesso à educação infantil}

As disparidades de acesso em relação à faixa etária, à etnia/cor, à localização (urbano/rural), à renda familiar e escolaridade dos pais/responsáveis, sobretudo da mãe, vêm sendo recorrentemente apontadas nos estudos sobre a oferta de educação infantil no Brasil, concorrendo para penalizar as crianças mais novas, as mais pobres e as não brancas. 
É preciso ressaltar que a redução ano a ano da participação de crianças, adolescentes e jovens no total da população brasileira, devido à intensa e rápida queda da fecundidade no país nas últimas décadas, pode configurar a existência de condições mais propícias para o melhor atendimento das necessidades da infância e de suas famílias, incluindo a educação infantil. De acordo com o IBGE (2009), na primeira infância (0 a 6 anos), a redução já ocorre não só em termos percentuais (de 13,2\% para $10,2 \%$ entre 1998 e 2008), mas também em números absolutos. Em 1998, a população desta faixa de idade era cerca de 21 milhões, tendo se reduzido para 19,4 milhões, em 2008. Outra consequência da baixa fecundidade é a presença percentual cada vez menor de famílias com crianças no país. Em 1998, do total das famílias brasileiras, 33,4\% incluíam crianças de 0 a 6 anos, percentual que passou para 25,2\%, em 2008.

Os dados da PNAD (IBGE, 2009) mostram que a taxa de escolarização das crianças na faixa de idade de 0 a 6 anos ainda é baixa, tendo atingido a cobertura de 45,8\%, em 2008. No entanto, quando analisamos esse índice de forma desagregada, verificamos que é cada vez mais generalizado o acesso à pré-escola, para crianças a partir de 4 anos de idade. Ao lado disso, verificamos taxas persistentemente baixas para o segmento das crianças menores de 3 anos de idade.

Chama, assim, a atenção o fato de que é na variável idade que observamos as maiores disparidades de acesso, em relação às variáveis localização, renda e etnia/cor.

Em 2001, apenas $10,6 \%$ das crianças de 0 a 3 anos frequentavam creches. No período 2001-2008, o atendimento de crianças em creche cresceu apenas 8,7 pontos percentuais, alcançando $18,1 \%$, ritmo insuficiente e ainda muito distante para o alcance da meta constante no PNE (2001), de terem matriculadas 50\% das crianças de 0 a 3 anos, em 2010. Tornar realidade o propósito aprovado na CONAE de alcançar a referida meta em 2012 e ter toda a demanda manifesta (desta faixa de idade) atendida em 2016 exige a adoção de ações e investimentos que busquem, de um lado, conhecer os déficits de atendimento e, de outro, conhecer a demanda por creche.

A desigualdade de acesso às creches em relação à variável renda ainda é grave, na medida em que a frequência de crianças pertencentes às famílias com renda per capita de até meio salário mínimo $(12,4 \%)$ foi 3,2 vezes menor do que a de crianças pertencentes a famílias com renda de três ou mais salários mínimos mensais $(39,5)$, em 2008. 
A proporção de crianças, na faixa etária de 4 a 6 anos, que frequentava escola em 2008 alcançou a média nacional de $80 \%$, índice que responde com anterioridade à meta prevista para 2010. A frequência à escola nesse grupo de idade também apresentou, em 2001 e 2008, diferenças consideráveis segundo as faixas de renda das famílias, ainda que em proporções menores às observadas em relação às creches. No entanto, desde o início desta década, conforme resultados das PNAD/IBGE, o atendimento de crianças de 4 a 6 anos com rendimento médio familiar acima de três salários mínimos está perto da universalização. Em 2004, $94,3 \%$ de crianças de 4 a 6 anos, de famílias de renda superior, já frequentavam a pré-escola, ao passo que as crianças de renda inferior apresentaram taxa de frequência de $63,2 \%$, evidenciando a enorme defasagem. Em 2008, as respectivas taxas de frequência foram de $98,8 \%$ para o primeiro segmento, com acesso praticamente universalizado, sendo de $77,1 \%$ para o segundo segmento de renda.

São igualmente encontradas diferenças significativas na frequência das crianças de 0 a 3 anos em relação à cor: as crianças negras apresentaram cobertura de $15,5 \%$, ao passo que as não negras ultrapassaram o percentual de 22\%, em 2008, ainda segundo dados do PNAD (IBGE, 2008).

Merecem destaque as baixas taxas de atendimento entre a população infantil da área rural. Apenas $6,4 \%$ das crianças entre 0 e 3 anos foram atendidas, enquanto na área urbana $19,6 \%$ estão na creche. $\mathrm{Na}$ faixa de 4 a 6 anos, 66\% das crianças são atendidas na área rural, enquanto na área urbana são $80,4 \%$.

Com o objetivo de avaliar se haveria diferenciais nas taxas de frequência à escola/creche de acordo com a estrutura da família, o PNAD (IBGE, 2008) analisou os resultados para as crianças filhas de mães que são pessoas de referência da família sem cônjuge, "ou seja, mães que, em princípio, necessitam sustentar suas famílias e, portanto, seriam alvo preferencial das políticas públicas na oferta de escolas de educação infantil" (IBGE, 2009, p. 137). Mesmo para as crianças com mães nesta situação, a taxa não atingia $20 \%$ na faixa de 0 a 3 anos, apenas ligeiramente superior à média nacional. Também foram observadas grandes diferenças nas taxas de frequência à creche de acordo com a situação econômica dessas mães: $18,5 \%$ para aquelas que viviam com até meio salário mínimo per capita e $46,2 \%$ para as que viviam com mais de três salários mínimos. A Tabela 2 apresenta a evolução das matrículas em creches e pré-escolas, no período de 2001 a 2009. 


\section{Tabela 2}

Matrículas em creches e pré-escolas, por dependência administrativa e localização Brasil - 2001 a 2009

Creche

\begin{tabular}{|c|c|c|c|c|c|c|c|c|c|}
\hline Ano & Total & Rural & $\%$ & Federal & Estadual & \multicolumn{2}{|c|}{ Municipal } & \multicolumn{2}{|c|}{ Particular } \\
\hline & & & & & & Total & $\%$ & Total & $\%$ \\
\hline 2001 & 1.093 .347 & 103.446 & 9,5 & 886 & 18.292 & 663.508 & 60,7 & 410.661 & 37,6 \\
\hline 2002 & 1.152 .511 & 98.210 & 8,5 & 709 & 17.955 & 698.643 & 60,6 & 435.204 & 37,8 \\
\hline 2003 & 1.237 .558 & 100.722 & 8,1 & 671 & 18.127 & 748.707 & 60,5 & 470.053 & 38,0 \\
\hline 2004 & 1.348 .237 & 101.940 & 7,6 & 721 & 14.993 & 828.352 & 61,4 & 504.171 & 37,4 \\
\hline 2005 & 1.414 .343 & 107.144 & 7,5 & 893 & 17.264 & 860.960 & 60,9 & 535.226 & 37,8 \\
\hline 2006 & 1.427 .942 & 101.666 & 7,1 & 933 & 17.582 & 898.945 & 63,0 & 510.482 & 35,7 \\
\hline 2007 & 1.579 .581 & 112.043 & 7,1 & 974 & 8.651 & 1.040 .670 & 66,0 & 529.286 & 33,5 \\
\hline 2008 & 1.751 .736 & 114.065 & 6,5 & 1.121 & 7.365 & 1.134 .944 & 64,8 & 608.306 & 34,7 \\
\hline 2009 & 1.896 .363 & 120.569 & 6,4 & 1.215 & 6.819 & 1.244 .731 & 65,6 & 643.598 & 33,9 \\
\hline
\end{tabular}

\section{Pré-Escola}

\begin{tabular}{|c|c|c|c|c|c|c|c|c|c|}
\hline Ano & Total & Rural & $\%$ & Federal & Estadual & \multicolumn{2}{|c|}{ Municipal } & \multicolumn{2}{|c|}{ Particular } \\
\hline & & & & & & Total & $\%$ & Total & $\%$ \\
\hline 2001 & 4.818 .803 & 658.642 & 13,7 & 1.626 & 317.861 & 3.275 .406 & 68,0 & 1.223 .907 & 25,4 \\
\hline 2002 & 4.977 .847 & 657.269 & 13,2 & 1.751 & 302.234 & 3.402 .909 & 68,4 & 1.270 .953 & 25,5 \\
\hline 2003 & 5.155 .676 & 675.708 & 13,1 & 1.787 & 302.336 & 3.532 .969 & 68,5 & 1.318 .584 & 25,6 \\
\hline 2004 & 5.555 .525 & 750.041 & 13,5 & 1.637 & 277.613 & 3.792 .629 & 68,3 & 1.483 .646 & 26,7 \\
\hline 2005 & 5.790 .670 & 835.559 & 14,4 & 1.668 & 249.001 & 4.026 .681 & 69,5 & 1.513 .320 & 26,1 \\
\hline 2006 & 5.588 .153 & 831.778 & 14,9 & 1.538 & 225.397 & 3.921 .291 & 70,2 & 1.439 .927 & 25,8 \\
\hline 2007 & 4.930 .287 & 775.830 & 15,7 & 1.167 & 168.994 & 3.727 .934 & 75,6 & 1.032 .192 & 20,9 \\
\hline 2008 & 4.967 .525 & 781.792 & 15,7 & 1.117 & 105.181 & 3.743 .531 & 75,4 & 1.117 .696 & 22,5 \\
\hline 2009 & 4.866 .268 & 784.199 & 16,1 & 1.239 & 70.152 & 3.664 .360 & 75,3 & 1.130 .983 & 23,2 \\
\hline
\end{tabular}

Fonte: MEC/INEP, Sinopses Estatísticas da Educação Básica, 2001 a 2009 
Evidencia-se a preponderância dos municípios na oferta total durante todo o período, atingindo $65,6 \%$ em creches e $75,3 \%$ em préescolas, em 2009. Isso empresta enorme complexidade à organização da oferta de educação infantil no país, se considerarmos os diferentes arranjos das políticas municipais, que se distanciam ou se aproximam do marco legal, e as disparidades e desigualdades que permanecem. Expressa, igualmente, o engajamento do setor público e a efetivação das competências federativas estabelecidas na nossa Constituição Federal.

Ainda segundo informações do MEC/INEP, a oferta rural, além de ser baixa, é praticamente exclusiva dos municípios. Em 2009, 94\% das matrículas rurais eram municipais e estavam concentradas no Nordeste, tendência que é encontrada desde o início da década.

Observamos também que, ao lado do crescimento das matrículas em creches no período, que foram duplicadas nos municípios, está havendo declínio na pré-escola desde o ano de 2005. Supomos que a migração das crianças de 6 anos para o ensino fundamental e a queda de fecundidade contribuem para essa tendência. No entanto, isso é preocupante, se levarmos em conta a defasagem de quase $22 \%$ na frequência das crianças pertencentes às famílias com mais baixo rendimento mensal per capita, em relação àquelas que pertencem às famílias com rendimentos acima de três salários mínimos mensais per capita, cuja frequência pode ser considerada universal. A universalização da pré-escola, para atingir as crianças dos meios populares das cidades e do campo, incluindo as indígenas e quilombolas, é objetivo que deve ser reforçado no novo PNE. Assim, a obrigatoriedade escolar estendida à pré-escola deve significar, mais que uma imposição às famílias, um meio de propiciar a universalização que oportunize experiências enriquecedoras e emancipadoras no percurso escolar de todas as crianças pequenas brasileiras.

\section{Formação e valorização dos profissionais}

Estudo divulgado recentemente sobre professores no Brasil (Gatti \& Barreto, 2009) mostrou que, no âmbito da educação básica, a educação infantil concentra os professores mais jovens, mulheres, não brancas, com menor escolaridade, que recebem os menores salários e executam jornadas de trabalho diárias e semanais mais extensas.

As metas do PNE (2001) sobre formação de professores para a educação infantil tinham como referência a LDBEN, que estabelecia a formação 
em nível superior para os docentes da educação básica, admitindo, como formação mínima para o exercício do magistério na educação infantil e nas quatro primeiras séries do ensino fundamental, a oferecida em nível médio, na modalidade Normal.

Informações divulgadas pelo Censo Escolar de 2007 (MEC/INEP, 2007) permitem constatar a predominância de professoras ( $97 \%$ são mulheres) formadas em nível de ensino médio na modalidade Normal, atuando na educação infantil, e a existência de diferenças em relação às creches e pré-escolas, e às regiōes do país. Mais professoras com a formação de nível superior no Sudeste e na pré-escola (59,3\%), prevalecendo as que possuem a formação de nível médio no Nordeste e na creche $(57,3 \%)$. A consulta à série histórica das estatísticas divulgadas pelo MEC/ INEP sobre formação de docentes na educação infantil, desde 2002, mostra também que houve alteração no quadro da formação, crescendo o número de docentes licenciadas em nível de ensino superior e diminuindo as que possuem apenas o ensino fundamental, completo ou incompleto: nas creches, $14,4 \%$ das funções docentes tinham formação superior completa, de acordo com o Censo do Professor de 2003 (INEP, 2003). Este estudo mostrava que, no mesmo ano, 22,5\% das funções docentes atuando na pré-escola apresentavam formação superior com licenciatura. Estudo inédito do mesmo Instituto, informando pela primeira vez o número de professores na educação básica, no lugar de quantidade de funções docentes, mostrou que a proporção de docentes com formação em nível superior com licenciatura cresceu na média nacional, sendo 37,2\% nas creches e $45,5 \%$ nas pré-escolas, de um total de 95.643 e 240.543 docentes, respectivamente. Isso representa importante avanço na qualidade do atendimento, pois são convergentes os resultados de pesquisas que mostram que a formação do profissional é condição indispensável para uma educação infantil de qualidade, entendida como uma efetiva política de bem-estar e de educação. Revela também uma aproximação da oferta pública e privada com o marco legal. No entanto, esses dados evidenciam que estamos longe de atingir a meta de $70 \%$ de docentes com formação superior nas creches e pré-escolas, conforme o PNE (2001). Observamos, no Documento Final da CONAE, que não constam metas quantitativas referentes aos professores da educação infantil.

Atualmente, a formação inicial superior para atuação nas séries iniciais do ensino fundamental e na educação infantil deve ocorrer no 
âmbito das universidades e em instituições de ensino superior, de acordo com as novas diretrizes curriculares para os cursos de Pedagogia.

O acompanhamento das metas do novo PNE exige que as informações quantitativas evidenciem um quadro mais preciso da formação e do trabalho no campo do cuidado e educação da primeira infância no país. Apesar de serem produzidas, estas informações não são divulgadas de forma desagregada, não sobressaindo, por exemplo, os dados sobre os respondentes das instituições particulares, comunitárias, filantrópicas e confessionais nos censos escolares. Não estão, igualmente, disponibilizadas informações sobre outros profissionais não docentes, que se ocupam de grupos de crianças e executam trabalho similar aos professores, exercendo funções pedagógicas, segundo se pode conhecer por meio de observaçóes e estudos em andamento.

Políticas governamentais nas diferentes esferas de governo, envolvendo instituiçôes formadoras de ensino superior públicas, são imprescindíveis para o alcance de metas concernentes, sempre articuladas com investimentos em valorização dos profissionais.

Ademais, as metas de expansão, universalização da pré-escola e atendimento à demanda manifesta nas creches evidenciam a necessidade de suprir a carência de professores na área.

\section{Convênios com creches e pré-escolas}

Com a aprovação, pelo Congresso Nacional, da Emenda Constitucional n. 53/2006 que criou o Fundo de Manutenção e Desenvolvimento da Educação Básica (FUNDEB), foram subvinculadas, pela primeira vez no país, as fontes de financiamento de creches e pré-escolas nos sistemas de ensino, estendidas à manutenção das creches/pré-escolas conveniadas com o poder público municipal.

A inclusão das creches foi resultado da pressão dos movimentos comunitários e da luta pela educação infantil, com ampla mobilização envolvendo a Campanha Nacional pelo Direito à Educação, o Movimento Interfóruns de Educação Infantil do Brasil (MIEIB), a União Nacional dos Dirigentes Municipais de Educação (UNDIME), a Confederação Nacional dos Trabalhadores em Educação (CNTE) e outros atores sociais, na interlocução com o MEC e o Congresso Nacional. Manifestações públicas e fóruns de discussão foram realizados, evidenciando posições e 
entendimentos diferenciados sobre o estatuto da creche comunitária e sobre a relação público-privado na educação e, em especial, na educação infantil brasileira. Essas discussões e as definiçôes legais para implementação do FUNDEB tornaram também necessária a tarefa de clarificar o que são os convênios, como são definidos e executados, sobretudo no âmbito das políticas municipais de educação.

Um dos aspectos marcantes do processo de expansão da educação infantil no Brasil, iniciado no final da década de 1970, foi a presença da sociedade, por meio de associações comunitárias ou de caráter filantrópico, na oferta de creches e pré-escolas, e a ação indutora do governo federal, por meio de programas sociais com forte apelo à "participação comunitária”, visando atingir a população pobre. Isso coincidiu com o processo de democratização da sociedade brasileira e com a eclosão da luta por creches nas periferias dos grandes centros urbanos.

Num contexto de forte centralização política e administrativa, e de reformas nas políticas de Previdência e Assistência Social, o governo federal (Governo Geisel) iniciou, em 1977, a implantação de um programa nacional, coordenado pela antiga Legião Brasileira de Assistência (LBA), de apoio às iniciativas da sociedade para ampliação ou implantação de atendimento à criança de 0 a 6 anos. Conhecido como "Projeto Casulo", o programa introduziu uma modalidade de financiamento público de determinados serviços sociais prestados à população por entidades de direito privado, de caráter filantrópico ou comunitário. Assim, estabeleceu-se uma relação sistemática e continuada, regulada por termo jurídico de convênio, entre governo federal e entidade social.

Esse modelo veio a se constituir, nas cidades do interior e nas capitais, na forma dominante de acesso à educação infantil das crianças pequenas que habitavam em bairros populares, favelas, vilas, em pequenos municípios ou no entorno das grandes cidades brasileiras. A partir de meados na década de 1980, muitos municípios adotaram também essa estratégia de financiamento de creches/pré-escolas, como mostram as experiências das prefeituras de São Paulo, Belo Horizonte e Rio de Janeiro, por exemplo, constituindo extensas redes de creches comunitárias/filantrópicas conveniadas, vinculadas às secretarias municipais de assistência, desenvolvimento ou bem-estar social, ao lado das chamadas creches diretas ou mantidas diretamente pelas prefeituras e das pré-escolas municipais. 
A Lei n. 11.494/2007, que regulamenta a implantação do FUNDEB, traz elementos definidores importantes em relação à distribuição dos recursos entre governo estadual e municípios, na proporção do número de alunos matriculados nas respectivas redes de educação básica pública presencial.

Estabelecem-se, pela primeira vez no Brasil, parâmetros legais para o repasse de recursos públicos da área educacional, definindo as obrigações das instituições conveniadas em relação ao serviço a ser prestado à população. Isso se deve, certamente, ao reconhecimento da presença relevante dos convênios na gestão da política de educação infantil dos municípios e à necessidade de regulação pela política nacional.

No artigo $8^{\circ}$ da citada Lei, as instituições comunitárias, confessionais ou filantrópicas sem fins lucrativos conveniadas com o poder público deverão, obrigatória e cumulativamente, além de comprovar finalidade não lucrativa:

I - oferecer igualdade de condições para o acesso e permanência na escola e atendimento educacional gratuito a todos os seus alunos;

IV - atender a padrões mínimos de qualidade definidos pelo órgão normativo do sistema de ensino, inclusive, obrigatoriamente, ter aprovados seus projetos pedagógicos;

V - ter certificado do Conselho Nacional de Assistência Social ou órgão equivalente, na forma do regulamento. (Brasil, 2007, p. 8)

Um passo importante para a constituição de uma política de convênios mais homogênea nacionalmente foi a publicação, em 2009, pelo MEC/SEB/COEDI, das Orientações sobre convênios entre secretarias municipais de educação e instituiçôes comunitárias, confessionais e filantrópicas sem fins lucrativos para a oferta de educação infantil (Brasil/MEC, 2009). É a primeira vez, desde a criação dessa modalidade de relação entre poder público e setor privado sem fins lucrativos para oferta de creches e préescolas, que o MEC elabora orientações sobre os convênios, buscando municiar conselhos, secretarias e instituiçôes da sociedade civil no acompanhamento e controle social dessa relevante ação pública. Isso se deve ao fato de que, até 2008, os maiores aportes de recursos federais para creches estavam alocados em programa do Ministério de Desenvolvimento Social e Combate a Fome (MDSCF), assim como a gestão dessa política (Brasil, 2006). 
Na Tabela 3 são apresentadas informaçôes sobre a participação das conveniadas nas matrículas de educação infantil no Brasil e regióes, no ano de 2009.

\section{Tabela 3}

Matrículas na educação infantil, em creches e pré-escolas conveniadas, por tipo de convênio com o poder público (Brasil e regiões geográficas - 2009)

\section{Creche}

\begin{tabular}{|l|c|c|c|c|c|c|}
\cline { 3 - 7 } \multicolumn{2}{c|}{} & \multicolumn{5}{c|}{ Conveniada com o poder público } \\
\hline $\begin{array}{l}\text { Brasil e } \\
\text { Regiōes }\end{array}$ & Total & Total & $\%$ & Estadual & Municipal & $\begin{array}{c}\text { Estadual e } \\
\text { Municipal }\end{array}$ \\
\hline Brasil & 1.896 .363 & 335.155 & 17,7 & 17.143 & 308.559 & 9.453 \\
\hline Norte & 80.741 & 4.701 & 5,8 & 1.456 & 3.106 & 139 \\
\hline Nordeste & 441.161 & 39.995 & 9,1 & 2.569 & 33.099 & 4.327 \\
\hline Sudeste & 913.390 & 212.386 & 23,3 & 3.434 & 205.962 & 2.990 \\
\hline Sul & 329.946 & 56.051 & 17,0 & 3.124 & 51.202 & 1.725 \\
\hline Centro-Oeste & 131.125 & 22.022 & 16,8 & 6.560 & 15.190 & 272 \\
\hline
\end{tabular}

\section{Pré-escola}

\begin{tabular}{|l|c|c|c|c|c|c|}
\cline { 3 - 7 } \multicolumn{2}{c|}{} & \multicolumn{5}{c|}{ Conveniada com o poder público } \\
\hline $\begin{array}{l}\text { Brasil e } \\
\text { Regiōes }\end{array}$ & Total & Total & $\%$ & Estadual & Municipal & $\begin{array}{c}\text { Estadual e } \\
\text { Municipal }\end{array}$ \\
\hline Brasil & 4.866 .268 & 315.146 & 6,5 & 37.644 & 258.758 & 18.744 \\
\hline Norte & 482.983 & 11.646 & 2,4 & 3.974 & 6.997 & 675 \\
\hline Nordeste & 1.657 .306 & 80.924 & 4,9 & 10.201 & 63.398 & 7.325 \\
\hline Sudeste & 1.941 .889 & 143.392 & 7,4 & 7.247 & 130.130 & 6.015 \\
\hline Sul & 497.766 & 58.072 & 11,7 & 7.321 & 47.627 & 3.124 \\
\hline Centro-Oeste & 286.324 & 21.112 & 7,4 & 8.901 & 10.606 & 1.605 \\
\hline
\end{tabular}

Fonte: MEC/INEP/DEED 
Em 2009, a creche conveniada representava 52,1\% das matrículas nos estabelecimentos de ensino privados. Isso evidencia a relevante participação do financiamento público na manutenção de parte das iniciativas privadas na oferta de educação infantil, segmento creches, no Brasil. Já a pré-escola conveniada representou $28 \%$ das matrículas na rede privada, quase um terço da oferta.

O debate da questão em diferentes fóruns do MIEIB permite constatar que a relação município-instituição conveniada assume diferenciadas formas, onde se observam: repasses de recursos financeiros a ser geridos pela conveniada, segundo critérios determinados; presença ou ausência de termo jurídico de cooperação; cessão de espaço físico da conveniada para o município/estado ou vice-versa; cessão de pessoal, em geral professores ou contratados temporários, do órgão público para a conveniada; repasse de gêneros alimentícios (que pode coexistir com o repasse de recursos financeiros). Infelizmente, ainda carecemos de estudos e sistematização sobre as políticas de convênio em curso na atualidade, que abordem os critérios, a legislação/normatização concernente, os itens financiados e os custos, as formas de relação público-privado. Os efeitos da proposta de extinção dos convênios precisam ser dimensionados, o que reforça a necessidade de estudos.

\section{Considerações finais}

O Documento Final da CONAE está sintonizado com o marco legal e a conceituação que vem sendo construída sobre a educação infantil como primeira etapa da educação básica, ofertada em espaços não domésticos, institucionais, de acordo com projeto pedagógico e com professores habilitados. Isso expressa a participação e o engajamento dos movimentos, instituições e especialistas comprometidos com a causa da infância brasileira, conforme defende Rosemberg (2010).

O breve diagnóstico da situação da escolarização da primeira infância no Brasil indica a necessidade de prosseguir com os objetivos de garantir a democratização do acesso na educação infantil, o que pressupõe qualidade. Tal desafio foi reconhecido nas propostas referendadas na CONAE.

As tendências de crescimento da educação infantil, nos últimos 10 anos, nas quais sobressaem as taxas de frequência persistentemente 
baixas em relação às creches, embasaram as metas para a ampliação da oferta pública nesse segmento. As metas anunciadas pelo PDE-Proinfância indicam possibilidades para significativa ampliação dessa oferta, mas, mesmo assim, atender, em dois anos, a 50\% das crianças de 0 a 3 anos parece meta irreal e superestimada.

Nessa perspectiva, conhecer déficits e apurar demandas por creche, por meio de pesquisas usando metodologias diversificadas, deveria integrar as metas para a educação infantil do próximo PNE, constituindo um dos elementos definidores de políticas públicas (e programas) na área. Além de conhecer demandas, um diagnóstico atual por meio da realização do Censo da Educação Infantil é outra tarefa governamental, a qual devia ser prevista para acontecer no próximo ano, com vistas a fornecer informaçôes e indicadores de acompanhamento das metas do novo PNE.

A sintonia dos planos nacionais de investimentos sociais e econômicos com os planos estaduais e municipais de educação, próxima etapa do planejamento educacional para a década, deve ser alvo das nossas atençôes, a fim de que as estratégias para alcance das metas levem em conta as peculiaridades e as tendências da oferta e não apresentem retrocessos.

A universalização da pré-escola, agora de frequência obrigatória, a proposta de congelamento das matrículas conveniadas em 2014 e a sua extinção em 2018 requerem, certamente, passos a serem estabelecidos, e ainda muitos debates e estudos, com estreito acompanhamento do MEC. As análises sobre as situações de atendimento nos municípios, que exibem realidades muito diversas, devem levar em conta que as creches comunitárias e filantrópicas também se constituem em nicho de mercado de trabalho de coordenadoras, professoras ou educadoras, mulheres das classes populares, que protagonizaram, desde a década de 1980, a expansão da educação infantil no Brasil. As creches comunitárias e filantrópicas são também instâncias de exercício do poder local (prefeitos, líderes comunitários, vereadores, filantropos), que trazem retorno eleitoral, prestígio e influência. Isso leva a considerar ser este é um dos pontos de tensão na implementação do novo PNE.

Observamos, finalmente, que a abordagem e a análise crítica das propostas da CONAE para a educação infantil são tarefas de toda a área educacional, na perspectiva sistêmica da educação básica e superior brasileira. A consolidação dos avanços e das realizações empreendidas 
ao longo da última década requer o reconhecimento das desigualdades e da enorme dívida que ainda acumulamos com a infância brasileira. A elaboração e a implementação do novo Plano Nacional de Educação são, certamente, uma grande oportunidade para colocarmos a educação da primeira infância nas prioridades nacionais.

Recebido e aprovado em setembro de 2010.

\section{Referências}

AGÊNCIA BOM DIA. Disponível em: <http://www.agenciabomdiajundiaí. com.br/notícias>. Acesso em: 23 jun. 2010.

BRASIL. Emenda Constitucional n. 53, de 19 de dezembro de 2006. Dá nova redação aos art. 7º, 23, 30, 206, 208, 211 e 212 da Constituição Federal e ao art. 60 do Ato de Disposições Constitucionais. Diário Oficial da Uniāo, Brasília, DF, 20 dez. 2006. Seção 1, p. 5-6.

BRASIL. Emenda Constitucional n. 59, de 11 de novembro de 2009. Acrescenta $\$ 3^{\circ}$ ao art. 76 do Ato das Disposições Constitucionais Transitórias para reduzir, anualmente, a partir do exercício de 2009, o percentual da Desvinculação das Receitas da União incidente sobre os recursos destinados à manutenção e desenvolvimento do ensino, de que trata o art. 212 da Constituição Federal, dá nova redação aos incisos I e VII do art. 208, de forma a prever a obrigatoriedade do ensino de quatro a dezessete anos e ampliar a abrangência dos programas suplementares para todas as etapas da educação básica, e dá nova redação ao $\$$ $4^{\circ}$ do art. 211 e ao $\$ 3^{\circ}$ do art. 212 e ao caput do art. 214 , com a inserção neste dispositivo de inciso VI. Diário Oficial da União, Brasília, DF, 11 nov. 2009. Seção 1, p. 8.

BRASIL. Lei n. 11.494, de 20 de junho de 2007. Regulamenta o Fundo de Manutenção e Desenvolvimento da Educação Básica e de Valorização dos Profissionais da Educação (Fundeb), de que trata o art. 60 do Ato das Disposições Constitucionais Transitórias; altera a Lei n. 10.195, de 14 de fevereiro de 2001; revoga dispositivos das Leis n. 9.424, de 24 de dezembro de 1996, 10.880, de 9 de junho de 2004, e 10.845, de 5 de março de 2004; e dá outras providências. Diário Oficial da Uniāo, Brasília, DF, 21 jun. 2007. Seção 1, p. 7-12. 
BRASIL. Ministério da Educação. Conselho Nacional de Educação (CNE). Indicaçóes para subsidiar a construção do Plano Nacional de Educação 2011-2020. Brasília, DF: MEC/CNE, 2009.

BRASIL. Ministério da Educação. Conselho Nacional de Educação (CNE). Parecer CNE/CEB n. 8/2010. Estabelece normas para a aplicação do inciso IX do artigo $4^{\circ}$ da Lei n. 9.394/96 (LDB), que trata dos padrôes mínimos de qualidade de ensino para a Educação Básica pública. Brasília, DF: MEC/CNE, 5 maio 2010.

BRASIL. Ministério da Educação. Conselho Nacional de Educação (CNE). Parecer CNE/CEB n. 12/2010. Diretrizes Operacionais para a matrícula no Ensino Fundamental e na Educação Infantil. Brasília DF: MEC/CNE, 8 jul. 2010. (Aguardando homologação)

BRASIL. Ministério da Educação. Secretaria de Educação Básica (SEB). Orientaçôes sobre convênios entre secretarias municipais de educação e instituiçôes comunitárias, confessionais e filantrópicas sem fins lucrativos para a oferta de educação infantil. Brasília, DF, 2009.

BRASIL. Ministério da Educação. Instituto Nacional de Estudos e Pesquisas Educacionais (INEP). Plano Nacional de Educação: subsídios para a elaboração dos planos estaduais e municipais de educação. Brasília, DF: MEC/INEP, 2001.

BRASIL. Ministério da Educação. Instituto Nacional de Estudos e Pesquisas Educacionais (INEP). Sinopses estatísticas da Educação Básica: 2001/2009. Brasília, DF: MEC/INEP, 2001/2009. Disponível em: <http:// www.inep.gov.br>. Acesso em: 21 jun. 2010.

BRASIL. Ministério do Planejamento, Orçamento e Gestão. Ministério do Desenvolvimento Social e Combate à Fome. Ministério da Educação. Relatório dos trabalhos realizados pelo GT criado pela Portaria Interministerial no 3.219, de 21 de setembro de 2005, e proposta de prorrogação das suas atividades. Brasília, DF, 2006.

CONFERÊNCIA NACIONAL DE EDUCAÇÃO (CONAE), 2010, Brasília, DF. Construindo o Sistema Nacional Articulado de Educação: o Plano Nacional de Educação, diretrizes e estratégias; Documento Final. Brasília, DF: MEC, 2010. 
GATTI, B.A.; BARRETO, E.S. (Coord.). Professores do Brasil: impasses e desafios. Brasília, DF: UNESCO, 2009.

INSTITUTO BRASILEIRO DE GEOGRAFIA E ESTATÍSTICA (IBGE). Sintese de indicadores sociais 2002: coordenação de população e indicadores sociais. Rio de Janeiro: IBGE, 2002. Disponível em: <http:// www.ibge.gov.br >. Acesso em: 29 jul. 2010.

INSTITUTO BRASILEIRO DE GEOGRAFIA E ESTATÍSTICA (IBGE). Sintese de indicadores sociais 2009: coordenação de população e indicadores sociais. Rio de Janeiro: IBGE, 2010. Disponível em: <http:// www.ibge.gov.br >. Acesso em: 29 jul. 2010.

ROSEMBERG, F. Educação infantil pós-FUNDEB: avanços e tensões. In: SouZA, G. (Org.). Educar na Infância: perspectivas histórico-sociais. São Paulo: Contexto, 2010. 